\title{
Higher-Order Sliding Mode Observer for Speed and Position Estimation in PMSM
}

\author{
Suneel K. Kommuri, ${ }^{1}$ Kalyana C. Veluvolu, ${ }^{1}$ M. Defoort, ${ }^{2}$ and Yeng C. Soh ${ }^{3}$ \\ ${ }^{1}$ School of Electronics Engineering, Kyungpook National University, Daegu 702-701, Republic of Korea \\ ${ }^{2}$ LAMIH, CNRS UMR 8201, Université Lille Nord de France and UVHC, 59313 Valenciennes, France \\ ${ }^{3}$ School of Electrical and Electronics Engineering, Nanyang Technological University, Nanyang Avenue, Singapore 639798 \\ Correspondence should be addressed to Kalyana C. Veluvolu; veluvolu@ee.knu.ac.kr
}

Received 17 March 2014; Accepted 26 April 2014; Published 27 May 2014

Academic Editor: Her-Terng Yau

Copyright (c) 2014 Suneel K. Kommuri et al. This is an open access article distributed under the Creative Commons Attribution License, which permits unrestricted use, distribution, and reproduction in any medium, provided the original work is properly cited.

\begin{abstract}
This paper presents a speed and position estimation method for the permanent magnet synchronous motor (PMSM) based on higher-order sliding mode (HOSM) observer. The back electromotive forces (EMFs) in the PMSM are treated as unknown inputs and are estimated with the HOSM observer without the need of low-pass filter and phase compensation modules. With the estimation of back EMFs, an accurate estimation of speed and rotor position can be obtained. Further, the proposed method completely eliminates chattering. Experimental results with a $26 \mathrm{~W}$ three-phase PMSM demonstrate the effectiveness of the proposed method.
\end{abstract}

\section{Introduction}

The permanent magnet synchronous motor (PMSM) has high efficiency, high torque to inertia ratio, and high power density, and hence it is popular for high performance motion control applications. Rotor speed estimation in a sensorless PMSM has been extensively studied [1-3] and is mandatory if speed control, that is, speed as a feedback, is employed. Field oriented control has received a lot of attention [3] in controlling the high performance PMSM drives. The objective is to control the stator currents represented by a vector to obtain the torque. Sensorless field oriented control of PMSM requires knowledge of the rotor position. Normally, the rotor position can be measured with an encoder or hall sensors. When the rotor position is available, it is straightforward to calculate the speed of the PMSM by simply differentiating the rotor position [4].

The presence of encoder can increase the hardware complexity, size, and cost and reduce the reliability of the drive. Also, the encoder is sensitive to environmental constraints such as vibration and temperature [5]. Its performance degrades under uncertain conditions and may not work well at high speeds. Hence, several works have focused on replacing the hardware sensor with the software sensor that is based on the available system measurements (voltages and currents) to estimate the rotor position and speed $[2,3]$.

Several methods are available for rotor position and/or speed estimation in a sensorless PMSM drive $[2,6]$. The main concerns regarding speed estimation are related to accuracy, magnitude and frequency of measured electrical quantities (applied voltages and currents), dependence on motor parameters, and dynamic behavior. An extended Kalman filter method and the Luenberger observer based methods are also available to construct full-order estimators based on the machine model [7].

Sliding mode principle has been popular for estimation and control in the presence of uncertainties $[3,8]$. Recently, sliding mode observers (SMOs) have been successful in the estimation of unknown inputs or faults $[9,10]$. Several first-order sliding mode observers have been applied for sensorless estimation and control of industrial drives [1114]. Many of the existing speed estimation techniques require low-pass filtering and an additional position compensation for the rotor $[15,16]$ for instance. A survey was recently conducted in [17] for the implementation of the sliding mode control. In [16], the cross-coupling terms of the $d-q$ current 
dynamics are treated as unknown disturbances. Decoupling terms with improper parameters can slightly degrade the system's performance. Integral sliding mode (ISM) controller with a switching output was developed [18] to overcome these disturbances. As a result, ISM can guarantee the robustness of the system starting from the initial time instance. However, the speed estimation based on ISM current control requires an additional low-pass filter, which introduces the delay, and which in turn reduces the system's phase margin and can cause instability. In [19], a high-speed SM observer is proposed for sensorless speed estimation in a PMSM. The selection of the boundary layer and the sliding mode gain depends on the speed, and the method is more suitable for constant speed applications. To further overcome the phasedistortion, a modified SMO based is designed [12]. This method employs a two-stage estimation process for rotor position estimation. Both the works $[12,19]$ employ a sigmoid function instead of the switching function in order to avoid chattering phenomenon.

Higher-order SMO's have been developed to overcome the disadvantages of first-order SMO [20-22]. The supertwisting algorithm (STA) (see [23]) provides finite time and exact convergence, even in the presence of bounded perturbations. To analyze the robustness of the STA for a wider class of disturbances, strict Lyapunov functions are developed in [20]. This Lyapunov function makes some additional modifications of the STA by including terms which improves its robustness and convergence properties [20]. Also, it can reduce the well-known chattering phenomenon. The HOSM observer designs in [24, 25] rely on STA for finitetime convergence. In the above methods, the performance was only verified through simulations in the absence of noise and experimental validation was not performed.

In [20], the STA is able to converge in finite time and tolerate perturbations that have a strong influence near the origin. In the eventuality of a linearly growing perturbation, the convergence of STA fails. In other words, it can be said that the STA is unable to endure globally a linearly growing perturbation. To compensate for this problem, a modified STA is proposed. The observer gain is tuned to withstand persistently exciting perturbation terms. It is directly responsible for handling the linear perturbation which is bounded by a value that depends on the computed derivative of the sliding surface. A comparative analysis of the proposed algorithm with classical STA shows a much better reduction in estimation error, with reduced chattering effect and faster response. Based on the above arguments, it can be concluded that the proposed modified STA offers better performance in comparison to the classical STA in the scenario when linearly growing perturbations are considered.

The main contribution of this paper lies in application of a modified version of STA to design a HOSM observer. The performance of the proposed design is validated through experiments on a PMSM. The motivation of this work is to provide the HOSM observer with the properties of finite time convergence and low chattering effect compared to the classical equivalent control obtained with a traditional firstorder SMO that requires a low-pass filter [3]. The observer enables the estimation of the rotor position and speed of the PMSM in real time while reducing the well-known chattering phenomenon. For example, in [15], cascaded SMO is proposed for the estimation of back EMFs and rotor speed. The method requires cascaded first-order SM observers and uses low-pass filtering for the unknown back EMFs estimation. The requirement of low-pass filtering results in a delay in the back EMFs estimation and the corresponding speed estimation has high chattering phenomenon. In the HOSM scheme, the unknown back EMFs are estimated using the sliding mode terms designed by the sliding mode observer from current dynamics of the PMSM. With the back EMFs accurately estimated, the rotor position and speed can be obtained algebraically. The proposed technique does not require any low-pass filtering and hence has no delay in the estimation.

$\lambda_{\max }(A)$ denotes the maximum eigenvalue of a matrix $A$; $\|A\|$ denotes the 2 -norm $\sqrt{\lambda_{\max }\left(A^{T} A\right)}$ of $A . \lambda_{\min }(A)$ represents its minimum singular value.

\section{PMSM Modeling and Problem Statement}

The model of the PMSM, in the stationary reference frame, can be described by the following system [6]:

$$
\begin{aligned}
& \frac{d i_{\alpha}}{d t}=\frac{-R}{L} i_{\alpha}-\frac{1}{L} e_{\alpha}+\frac{1}{L} V_{\alpha}, \\
& \frac{d i_{\beta}}{d t}=\frac{-R}{L} i_{\beta}-\frac{1}{L} e_{\beta}+\frac{1}{L} V_{\beta}
\end{aligned}
$$

with

$$
\begin{gathered}
e_{\alpha}=-K_{E} \omega_{s} \sin \theta_{s}, \\
e_{\beta}=K_{E} \omega_{s} \cos \theta_{s}, \\
\frac{d \omega_{s}}{d t}=\frac{P}{J} \phi_{m}\left(-\sin \theta_{s} i_{\alpha}+\cos \theta_{s} i_{\beta}\right)-\frac{f_{v}}{J} \omega_{s}-\frac{T_{l}}{J} .
\end{gathered}
$$

The back EMF equations involve the dynamics of speed and position. The voltages $V_{\alpha}$ and $V_{\beta}$ and currents $i_{\alpha}$ and $i_{\beta}$ are the known quantities. The objective is to design an observer to estimate the back electromotive forces (EMFs) from (1) using the available measurements. Accurate estimation of back EMF will result in accurate estimation of speed and position.

\section{High Order Sliding Mode Observer}

Let us note that the extra terms $\left(e_{\alpha}, e_{\beta}\right)$ of the plant dynamics in (1) act like unknown inputs. The idea is to use higherorder sliding modes on both $\alpha$ and $\beta$ axes to estimate these unknown inputs.

Applying the same design principles as for variable structure control, the observer trajectories are constrained to evolve after a finite time on a suitable sliding manifold. Hence, the sliding motion provides an estimate (asymptotically or in finite time) of the system states. In the following, a HOSM observer will be designed to estimate the unknown inputs. 
For the implementation of the sliding mode observer, the following sliding surfaces are selected:

$$
\begin{aligned}
& s_{\alpha}(t)=\widehat{i}_{\alpha}-i_{\alpha}, \\
& s_{\beta}(t)=\widehat{i}_{\beta}-i_{\beta},
\end{aligned}
$$

where $\hat{i}_{\alpha}$ and $\hat{i}_{\beta}$ are estimated currents and $i_{\alpha}$ and $i_{\beta}$ are actual currents.

With the PMSM model defined in (1), the observer can be designed as follows:

$$
\begin{aligned}
& \frac{d \hat{i}_{\alpha}}{d t}=\frac{-R}{L} \widehat{i}_{\alpha}+\frac{1}{L} V_{\alpha}+\frac{1}{L} v_{1}(t), \\
& \frac{d \hat{i}_{\beta}}{d t}=\frac{-R}{L} \widehat{i}_{\beta}+\frac{1}{L} V_{\beta}+\frac{1}{L} v_{2}(t) .
\end{aligned}
$$

The sliding mode terms are given by

$$
\begin{aligned}
& v_{1}(t)=-K_{1} \phi_{1}\left(s_{\alpha}(t)\right)-K_{2} \int_{0}^{t} \phi_{2}\left(s_{\alpha}(t)\right) d t \\
& v_{2}(t)=-K_{1} \phi_{1}\left(s_{\beta}(t)\right)-K_{2} \int_{0}^{t} \phi_{2}\left(s_{\beta}(t)\right) d t
\end{aligned}
$$

where

$$
\begin{gathered}
\phi_{1}\left(s_{\alpha}(t)\right)=s_{\alpha}(t)+K_{3}\left|s_{\alpha}(t)\right|^{1 / 2} \operatorname{sign}\left(s_{\alpha}(t)\right), \\
\phi_{2}\left(s_{\alpha}(t)\right)=s_{\alpha}(t)+\frac{K_{4}^{2}}{2} \operatorname{sign}\left(s_{\alpha}(t)\right) \\
+\frac{3}{2} K_{4}\left|s_{\alpha}(t)\right|^{1 / 2} \operatorname{sign}\left(s_{\alpha}(t)\right),
\end{gathered}
$$

where $K_{1}, K_{2}, K_{3}$, and $K_{4}$ are appropriately designed positive constants. Similarly, the functions $\phi_{1}\left(s_{\beta}(t)\right)$ and $\phi_{2}\left(s_{\beta}(t)\right)$ can be obtained by replacing $s_{\alpha}(t)$ with $s_{\beta}(t)$ in (7).

3.1. Sliding Mode Stability. To prove the stability of the observer system, the time derivatives of the sliding surfaces are obtained from (1) and (5) as

$$
\begin{aligned}
& \dot{s}_{\alpha}=\frac{-R}{L} s_{\alpha}+\frac{1}{L} e_{\alpha}+\frac{1}{L} v_{1}(t), \\
& \dot{s}_{\beta}=\frac{-R}{L} s_{\beta}+\frac{1}{L} e_{\beta}+\frac{1}{L} v_{2}(t) .
\end{aligned}
$$

From (2) and (3), we can establish the boundedness of back EMFs. At least locally, there are positive constants $\rho_{1}$ and $\rho_{2}$ such that the following terms are bounded as follows:

$$
\begin{gathered}
\left|\dot{e}_{\alpha}\right| \leq \rho_{1}, \\
\left|\dot{e}_{\beta}\right| \leq \rho_{2}
\end{gathered}
$$

for some positive constants $\rho_{1}$ and $\rho_{2}$. The above condition (9) is not restrictive since $\omega_{s}, T_{l}$, and $e_{\alpha}$ and $e_{\beta}, i_{\alpha}$, and $i_{\beta}$ are continuous on a compact set.

Theorem 1. With the condition (9), the sliding dynamics $s_{\alpha}$ and $s_{\beta}$ are stabilized towards zero in finite time.

Proof. See Proposition A.3 in the appendix.
TABLE 1: Motor parameters.

\begin{tabular}{lcc}
\hline Parameters & & Values \\
\hline Rating & $\omega$ & $26[\mathrm{~W}]$ \\
Speed & $R$ & $4000[\mathrm{r} / \mathrm{min}]$ \\
Stator resistance & $L$ & $2.4[\Omega]$ \\
Stator inductance & $K_{E}$ & $0.65[\mathrm{mH}]$ \\
Back EMF constant & $J$ & $0.156[\mathrm{Vs} / \mathrm{rad}]$ \\
Inertia & $f_{v}$ & $0.004 \times 10^{-4}\left[\mathrm{Kg} \cdot \mathrm{m}^{2}\right]$ \\
Viscous friction & $\phi_{m}[\mathrm{Nm} \cdot \mathrm{s} / \mathrm{rad}]$ \\
Rotor flux & $P$ & 0.025 \\
Number of pole pairs & & 4 \\
\hline
\end{tabular}

3.2. Speed and Rotor Position Estimation. According to Theorem 1, the origin of system (8) has a finite time stable equilibrium. In the sliding mode, we have $s_{\alpha}=\dot{s}_{\alpha}=0$ and $s_{\beta}=\dot{s}_{\beta}=0$. The reduced order dynamics of system (8) becomes

$$
\begin{aligned}
& 0=-K_{2} \int_{0}^{t} \phi_{2}\left(s_{\alpha}(t)\right) d t+e_{\alpha}, \\
& 0=-K_{2} \int_{0}^{t} \phi_{2}\left(s_{\beta}(t)\right) d t+e_{\beta} .
\end{aligned}
$$

Hence a smooth estimation of the unknown back EMFs can be obtained in finite time as follows:

$$
\begin{aligned}
& \widehat{e}_{\alpha}=K_{2} \int_{0}^{t} \phi_{2}\left(s_{\alpha}(t)\right) d t, \\
& \widehat{e}_{\beta}=K_{2} \int_{0}^{t} \phi_{2}\left(s_{\beta}(t)\right) d t .
\end{aligned}
$$

Using the estimated back EMF voltages, the position of the rotor can be calculated as

$$
\widehat{\theta}_{s}=-\tan ^{-1}\left(\frac{\widehat{e}_{\alpha}}{\hat{e}_{\beta}}\right) .
$$

Also, with estimated back EMFs, using (2), the speed can be computed algebraically as

$$
\widehat{\omega}_{s}=\frac{1}{K_{E}} \sqrt{\widehat{e}_{\alpha}^{2}+\widehat{e}_{\beta}^{2}}
$$

The speed estimation only uses the EMF constant $K_{E}$ and the estimated back EMFs $\widehat{e}_{\alpha}$ and $\widehat{e}_{\beta}$. The proposed HOSM observer provides the properties of finite time convergence and low chattering effect compared to the classical equivalent control obtained using a low-pass filter [15].

\section{Experimental Results}

Experiments are performed with the three-phase $26 \mathrm{~W}$ PMSM. The specifications and parameters are provided in Table 1. The motor used in the experimental setup is a TBL- $i$ model TS4632N2050E510 3-phase PMSM. The PMSM is powered by a Fairchild FSB50325S smart power module which includes 6 fast-recovery MOSFET (FRFET) inverters and 3 half-bridge high voltage integrated circuits (HVICs) 


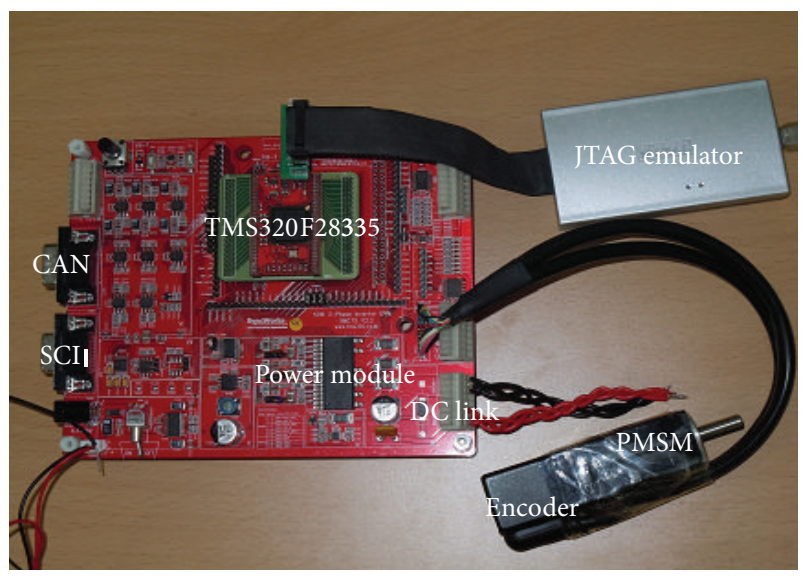

FIGURE 1: Experimental setup.

for FRFET gate driving. Since it employs FRFET as a power switch, it has much better robustness and larger safe operation areas (SOA) than that using an IGBT-based power module or one-chip solution. The experimental setup is shown in Figure 1. The space vector modulation (SVM) algorithm is used as modulation strategy and switching frequency of the PWM inverter is $15 \mathrm{kHz}$. SMC 75 evaluation module with TMS320F28335 DSP controller is used. It contains Texas Instruments 32-bit floating point DSP as well as analog interfaces and JTAG emulator port. The board has analog-todigital converter (A/D) with 16 channels. All the control variables are monitored using graph window of Code Composer Studio (CCS v3.3) after being converted to analog signals through the digital-to-analog (D/A) converter. Real motor speed $\left(\omega_{s}\right)$ is measured using a high-resolution incremental encoder with 2000 pulses/rotation and the estimated speed $\left(\widehat{\omega}_{s}\right)$ is obtained with the proposed HOSM scheme. The stator currents of the PMSM are measured from the current sensors and they are sent to TMS320F 28335 via A/D converters. In the same way, stator voltages are calculated using dc-bus voltage sensors and duty cycles of the inverter when the switching functions are known.

Three-phase currents and voltages are transformed to two-phase stationary $(\alpha-\beta)$ reference frame. They are again transformed to rotating $(d-q)$ reference frame for the control. PI (proportional and integral) controllers are used to regulate the $d, q$ synchronous frame currents $i_{q}$ and $i_{d}$. A functional block diagram for the overall scheme is depicted in Figure 2. The PMSM drive is operated in speed control mode. The speed is also regulated using a PI controller to generate the reference current $i_{q}^{\text {ref }}$ in the $q$-axis. The reference current in the $d$-axis $i_{d}^{\text {ref }}$ is set to 0 . For the implementation of HOSM observer, the sliding mode gains are selected as follows: $K_{1}=$ $0.7, K_{2}=60, K_{3}=35$, and $K_{4}=4.5$. The initial conditions for the estimator are chosen as $\widehat{x}(0)=\left[\begin{array}{llll}0 & 0 & 0 & 0\end{array}\right]$.

Several experiments have been performed to validate the proposed HOSM scheme. In the first part, we present the results performance of the proposed method under noload conditions for ramp change and step change and in the later part, similar experiments are conducted under loading

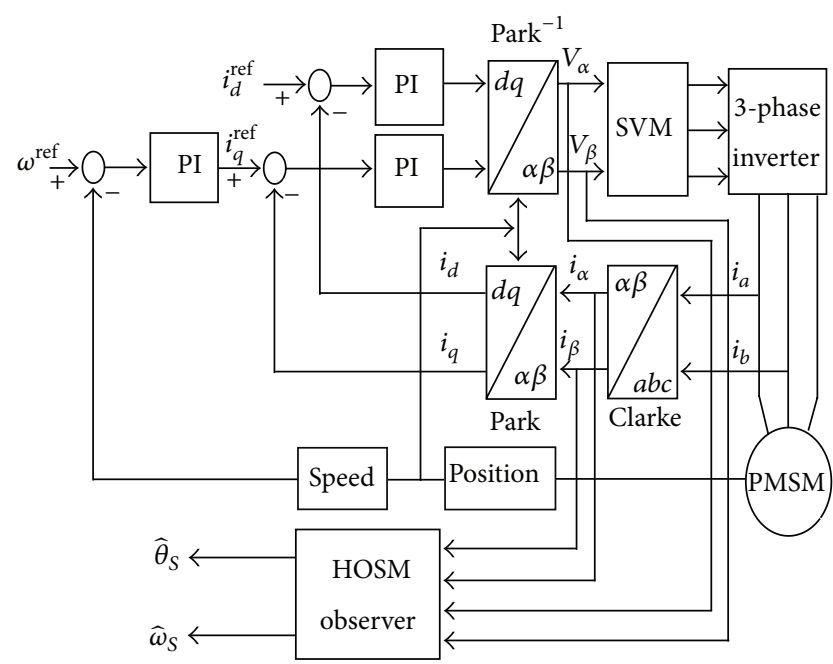

FIGURE 2: Functional block diagram for the overall scheme.

condition. For comparison, the results obtained with firstorder sliding mode observer are also presented.

4.1. Under No-Load Condition. In the first experiment, a constant speed reference $2000 \mathrm{rpm}$ is provided for the first $0.3 \mathrm{~s}$; a ramp input for the next $0.4 \mathrm{~s}$ followed by a constant speed of $3500 \mathrm{rpm}$ as shown in Figure 3(b) is employed. The real currents of the PMSM for the first experiment are shown in Figure 3(a). The encoder speed and position are provided in Figures $3(\mathrm{~b})$ and $3(\mathrm{c})$. The actual speed $\left(\omega_{s}\right)$ exactly follows the reference speed considered above. Presence of measurement noise can be clearly observed in $\left(i_{\alpha, \beta}\right)$ and $\left(\omega_{s}, \theta_{s}\right)$. With the proposed observer, the estimated currents and estimation error are shown in Figures 4(a) and 4(b). Real and estimated currents are very similar in both magnitude and phase using the proposed method. Figure 4(c) depicts the estimated back EMFs obtained using (11). Despite the noisy currents, the back EMFs are relatively smooth, which conforms the theoretical claim of the proposed approach. The estimated speed computed analytically from back EMFs with (13) is shown in Figure 4(d), which exactly tracks actual speed $\left(\omega_{s}\right)$ and is shown for the comparison. The convergence accuracy depends on the accurate estimation of the back EMF components and the back EMF constant $K_{E}$. The HOSM scheme enables a good reconstruction of the PMSM speed. Figures 4(e) and 4(f) show the estimated rotor position and estimation error. The estimated rotor position is robust with respect to noise measurements and exactly matches with the actual rotor position without any phase delay. So, the estimated rotor position can be used instead of the measured one in the vector control of PMSM drive. In usual practice, the values of $R$ and $L$ are not accurately known. To test the robustness, the parameters ( $R$ and $L$ ) values are varied by $\pm 10 \%$ and several experiments are conducted. Similar performance was obtained in comparison to results presented in Figure 4.

For comparison, the results obtained with conventional sliding mode observer [3] are shown in Figure 5. The sliding 


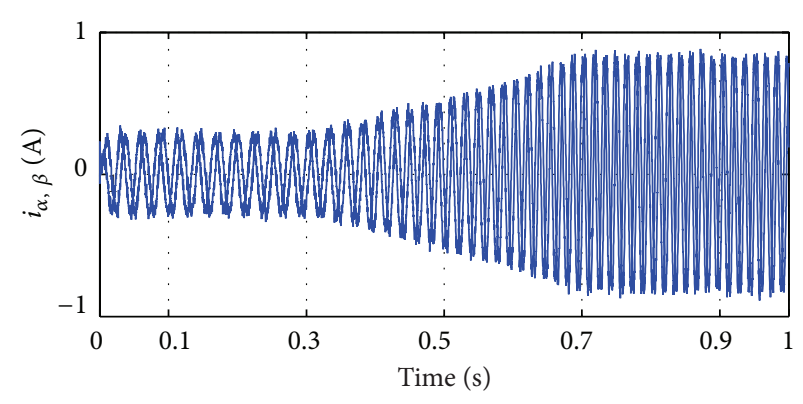

(a)

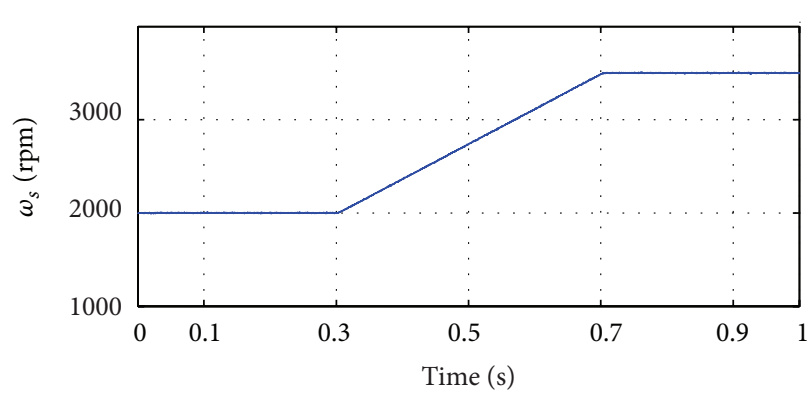

(b)

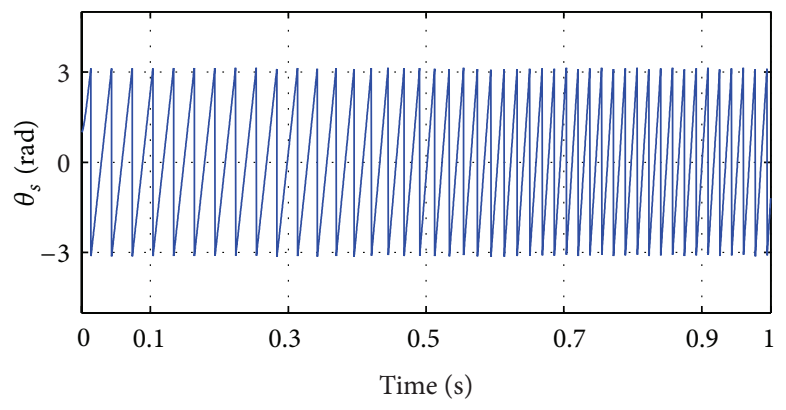

(c)

Figure 3: (a) Actual currents. (b) Actual speed. (c) Actual rotor position.

mode gain is set to 50 for the observer design. The presence of noise in the estimated currents (Figure 5(a)) highly affects the estimation of back EMFs as shown in Figure 5(c). The estimated back EMFs which correspond to the equivalent controls are obtained by filtering the switching functions of the observer with a $40 \mathrm{~Hz}$ low-pass filter. A proper boundary layer is required to overcome the chattering phenomenon. The speed and position estimate in Figures 5(d)-5(f) expose the problems with the conventional sliding mode observer for back EMF estimation. Also, the estimated speed has more noise compared to the speed estimate with the HOSM observer shown in Figure 4(d). The rotor position error in Figure 5(f) compared to Figure 4(f) clearly highlights the accuracy obtained with proposed method. Low-pass filtering clearly affects the estimation accuracy. The parameters for the first-order sliding mode are well-tuned to achieve the best possible results. Errors are mainly due to filtering and the use of sigmoid function to avoid the chattering phenomenon.

In the second experiment, a step change in speed is provided as reference. In this experiment, the speed estimate and position estimation error obtained with the proposed HOSM scheme for the step reference are shown in Figure 6. Figure 6(a) shows the estimated and actual speeds obtained using the proposed HOSM observer and Figure 6(b) shows the estimation error between the estimated and actual rotor positions. It can be seen from Figure 6(b) that the estimation has no delay with the proposed approach. For comparison, the results obtained with conventional first-order SMO are shown in Figure 7. Figure 7(a) shows the estimated and actual speeds obtained using the first-order SMO and Figure 7(b) shows the estimation error between the estimated and actual rotor positions. Although, the estimated speed follows the actual speed, it contains more noise compared to the proposed HOSM observer. These results further highlight the robustness of the proposed method in the presence of noise. Further the chattering phenomenon is completely eliminated and accurate position estimation can be obtained even in the presence of measurement noise.

4.2. Under Loading Condition. To test the performance of the proposed method, a mechanical load $J_{L}=0.07436 \mathrm{~kg} \cdot \mathrm{cm}^{2}$ is connected to the motor. Same set of parameters considered for no-load are employed for loading condition to test the robustness of the observer to parametric variations. The results obtained with HOSM observer for a ramp change are shown in Figure 8. Figures 8(a) and 8(b) show the estimated currents and their errors obtained using the proposed HOSM observer. It can be observed from Figure 8(b) that the estimated and actual currents exactly match each other. Figure 8(c) shows the estimated unknown back EMFs which are relatively smooth. The corresponding estimated speed calculated using (13) and the actual speed are depicted in Figure $8(\mathrm{~d})$. The estimated rotor position and the estimation error are shown in Figures 8(e) and 8(f). For comparison the estimated and actual speeds obtained with first-order SMO are shown in Figure 9(a) and the corresponding position estimation error is shown in Figure 9(b). In the final experiment under loading condition, step-like input reference is provided for the system; the results obtained with proposed method and first-order SMO are shown in Figure 10 and Figure 11, respectively. Figures 10(a) and 10(b) show the estimated, actual speeds and position estimation error obtained with the proposed HOSM observer, while Figures 11(a) and 11(b) show the estimated, actual speeds and position estimation error obtained with the first-order SMO. Under loading, the noise level is higher and the position estimation error slightly 


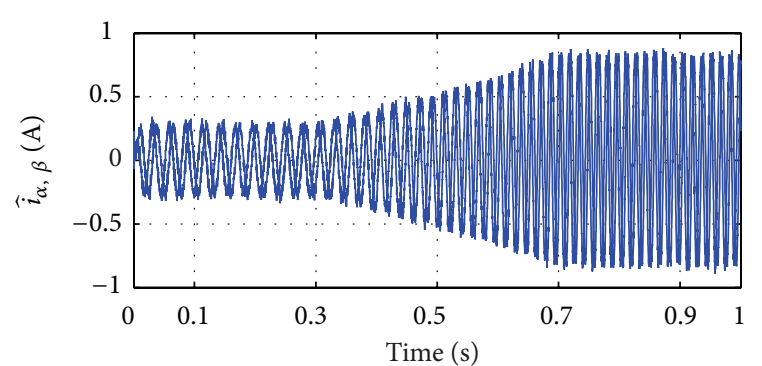

(a)

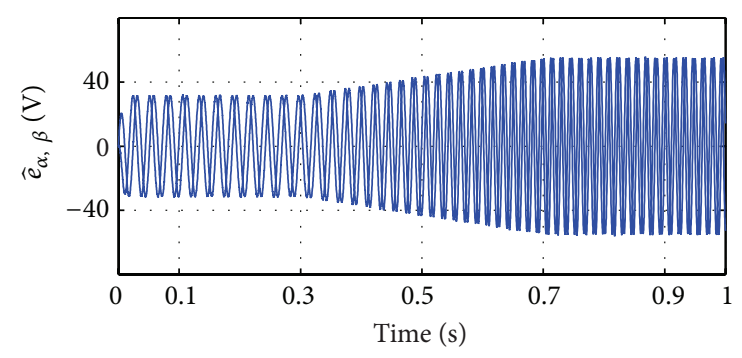

(c)

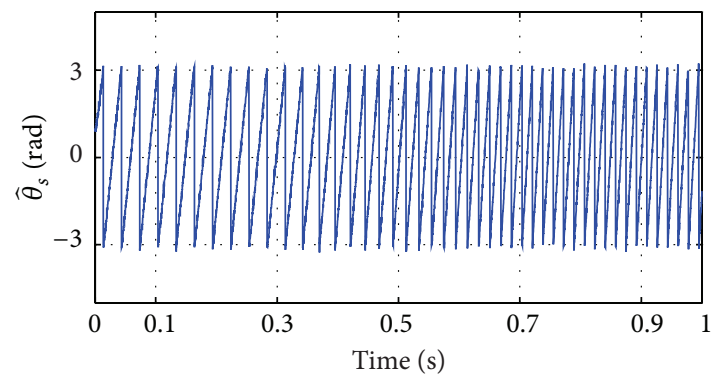

(e)

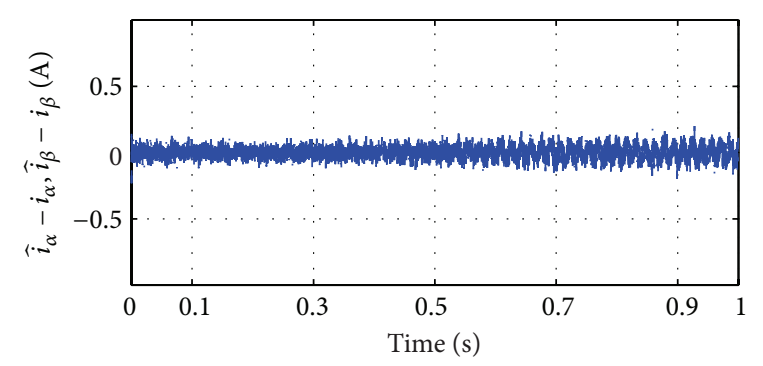

(b)

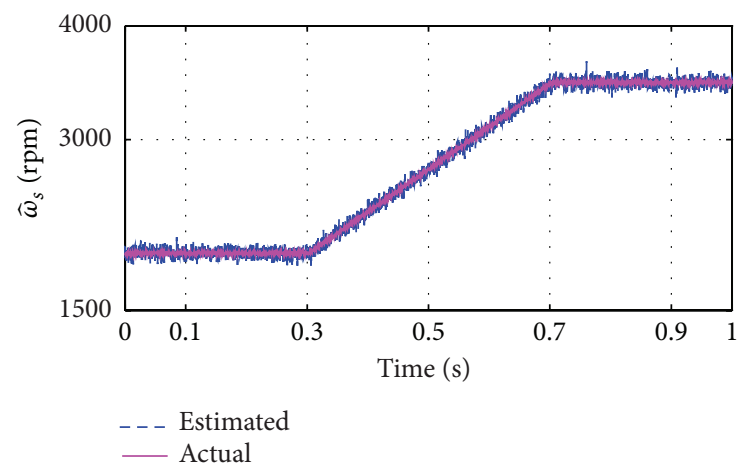

(d)

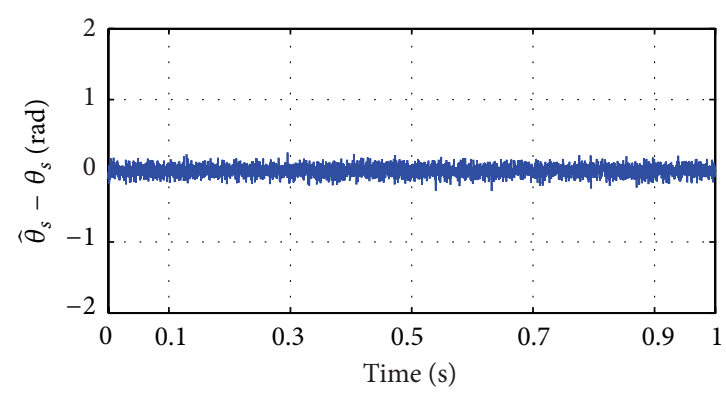

(f)

Figure 4: Estimation using higher-order sliding mode observer under no-load. (a) Estimated currents. (b) Estimation current error. (c) Estimated back EMFs. (d) Estimated speed. (e) Estimated rotor position. (f) Estimation rotor position error.

increases. However, the speed and position estimation remain robust with the proposed observer when compared to firstorder SMO. Due to parametric uncertainty, the speed estimation with proposed HOSM method shows a very small steady state error at $90 \%$ of the rated speed (Figures $8(\mathrm{~d})$ and $10(\mathrm{a})$ ). Under loading, the speed and position estimation with firstorder SMO are highly affected. Further tuning of the observer parameters can overcome the problem.

From the implementation, one can conclude the following.

(1) The HOSM method requires the proper selection of sliding mode gains $K_{1}, K_{2}, K_{3}$, and $K_{4}$. The sliding mode gains should satisfy the conditions given by (A.15)-(A.16) for the desired speed range. If the motor operates in wide speed range, the sliding mode gains must be appropriately selected.

(2) Since the quality of the speed estimate highly depends on the estimated back EMFs, it deteriorates when more noisy back EMFs (obtained due to high gains) are used in the calculation. Compared to existing methods, the proposed scheme provides good rotor speed and position estimation without phase delay in the presence of noise. Further, one should note that sensorless speed estimation methods based on back EMFs fail at very low speeds and standstill.

(3) It should be pointed out that a chattering phenomenon occurs using the conventional SM observer [15]. Therefore, in first-order SM observer, the signum function is used as switching function. The speed estimate is approximated by low-pass filtering the discontinuous switching functions. This delay should be compensated with an additional phase compensation loop. As low-pass filtering is eliminated with the proposed method, an additional phase compensation loop is not required. 


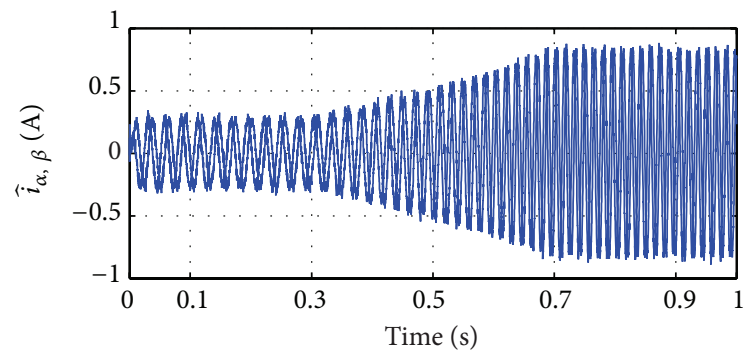

(a)

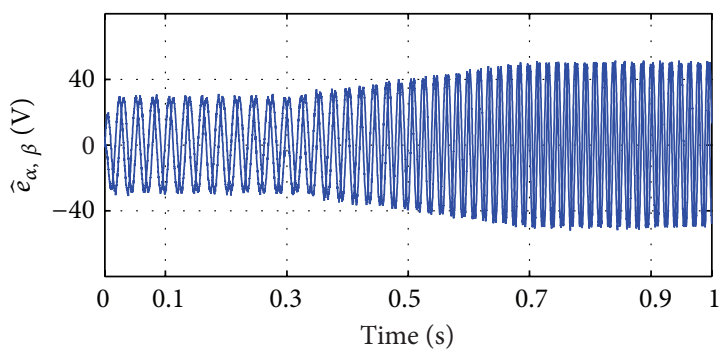

(c)

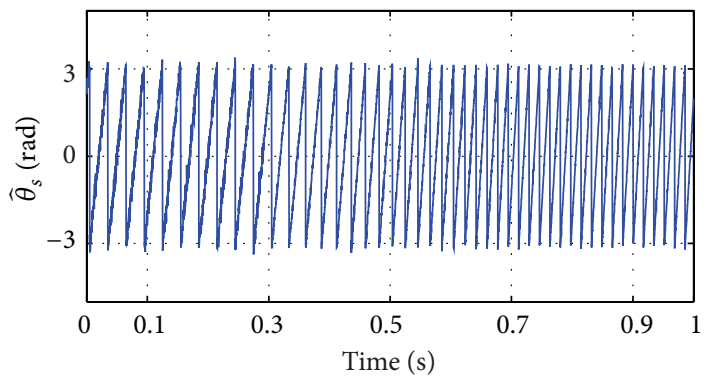

(e)

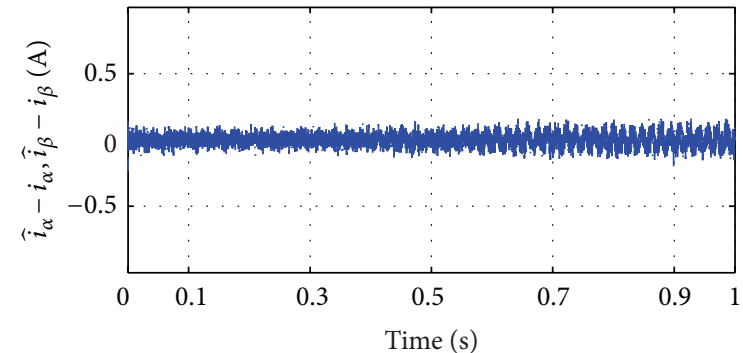

(b)

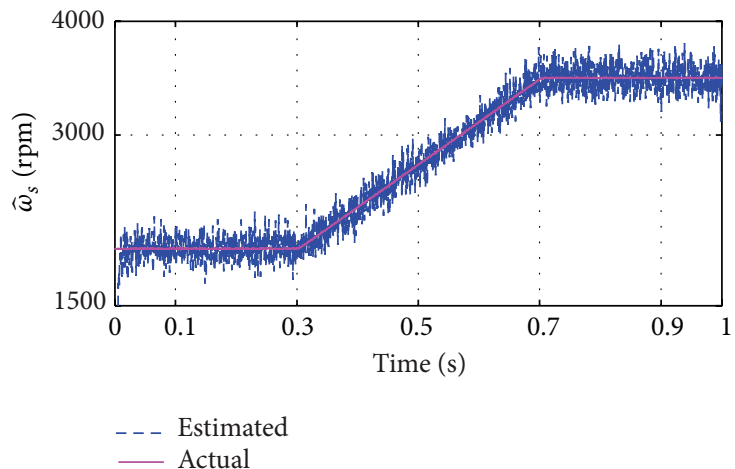

(d)

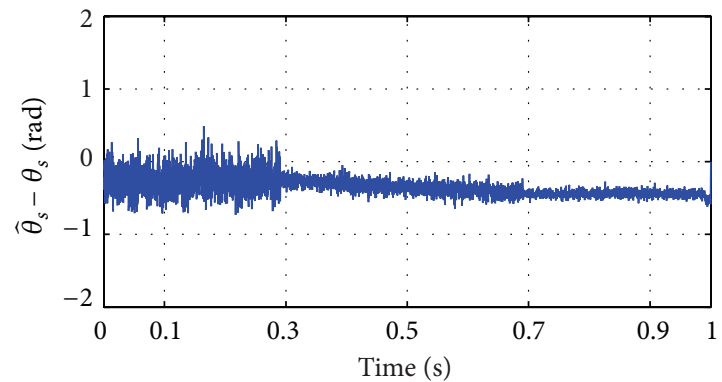

(f)

FIGURE 5: Estimation using conventional first-order sliding mode observer under no-load. (a) Estimated currents. (b) Estimation current error. (c) Estimated back EMFs. (d) Estimated speed. (e) Estimated rotor position. (f) Estimation rotor position error.

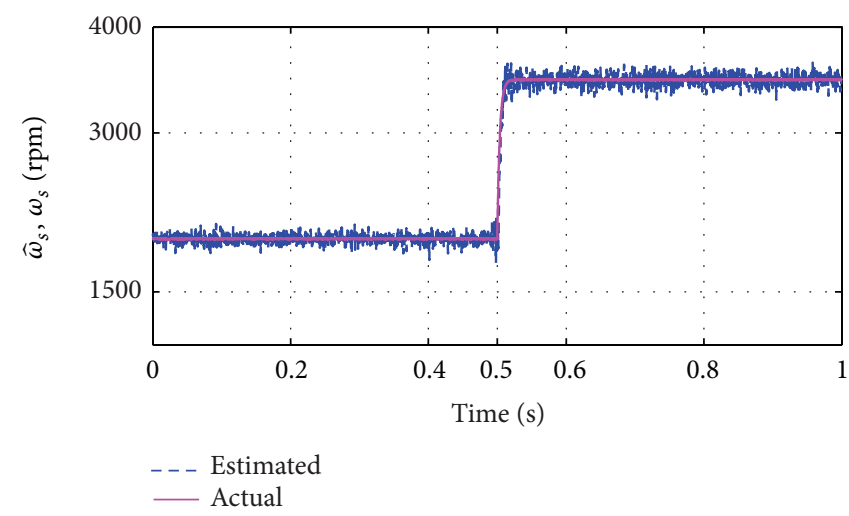

(a)

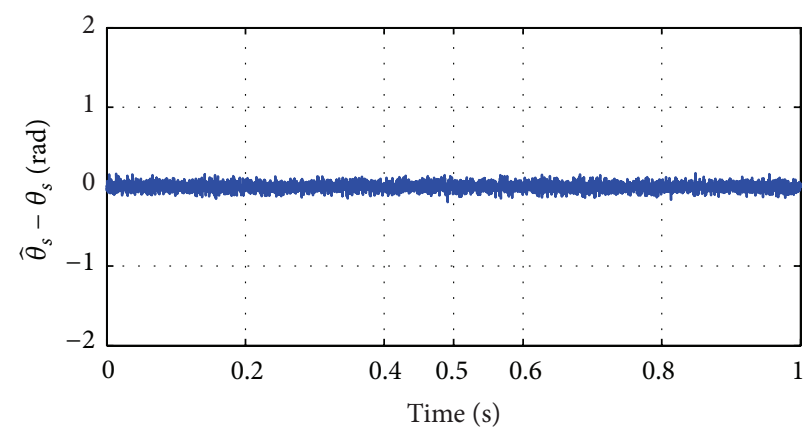

(b)

FIGURE 6: With proposed HOSM method under no-load: (a) Actual and estimated speed. (b) Rotor position estimation error. 


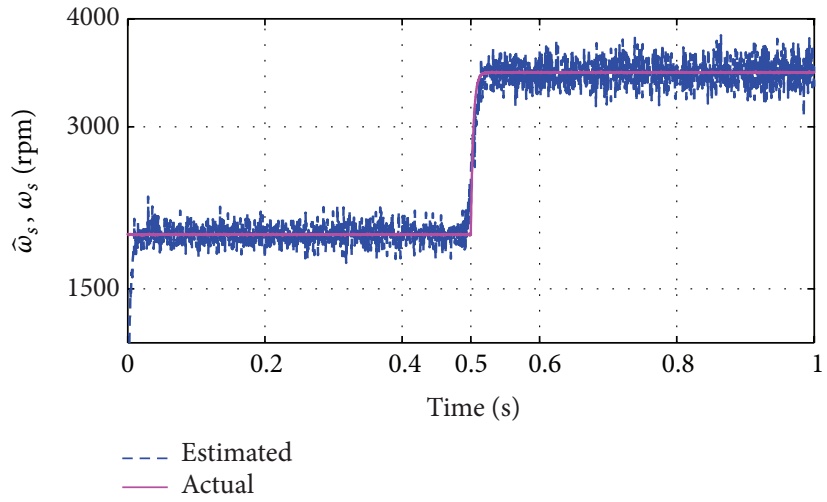

(a)

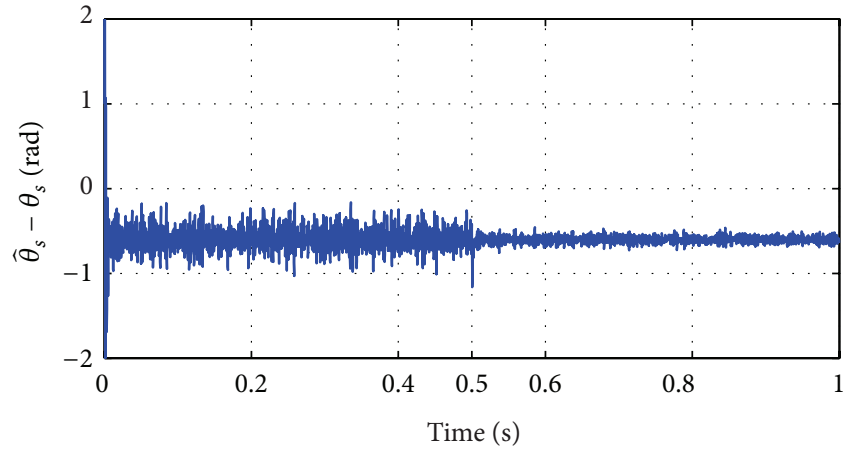

(b)

FIGURE 7: With conventional first-order SMO under no-load: (a) Estimated speed. (b) Rotor position estimation error.

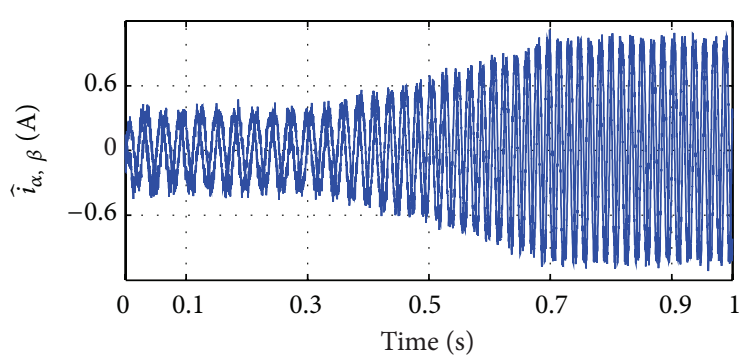

(a)

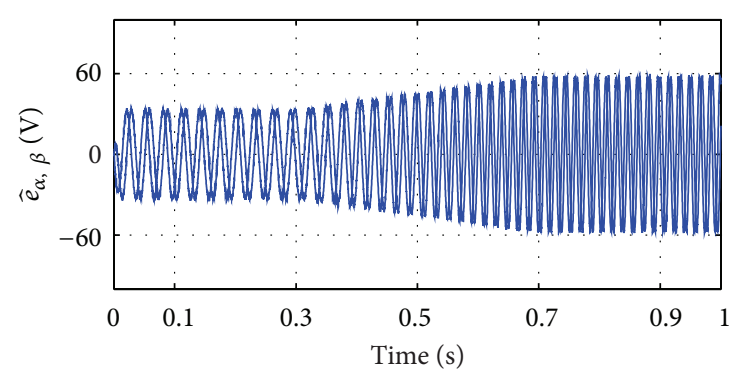

(c)

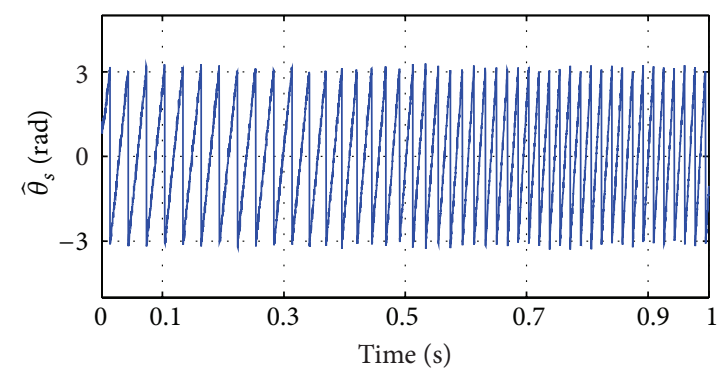

(e)

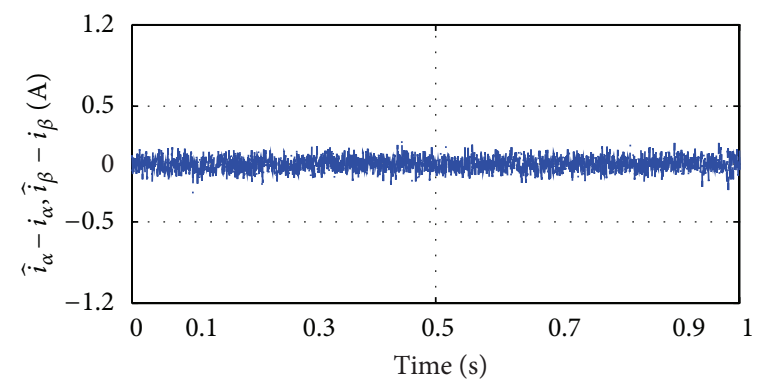

(b)

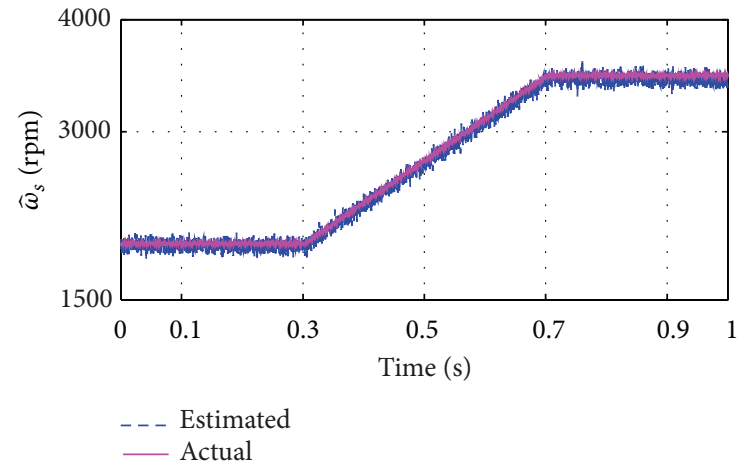

(d)

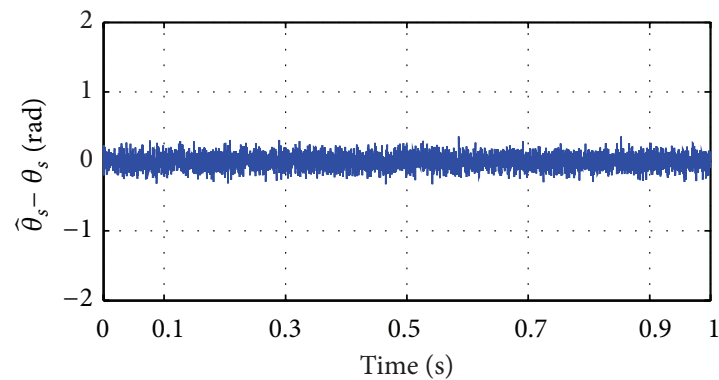

(f)

FIGURE 8: With proposed HOSM method under load: (a) Estimated currents. (b) Estimation current errors. (c) Estimated back EMFs. (d) Estimated speed. (e) Estimated rotor position. (f) Rotor position error. 


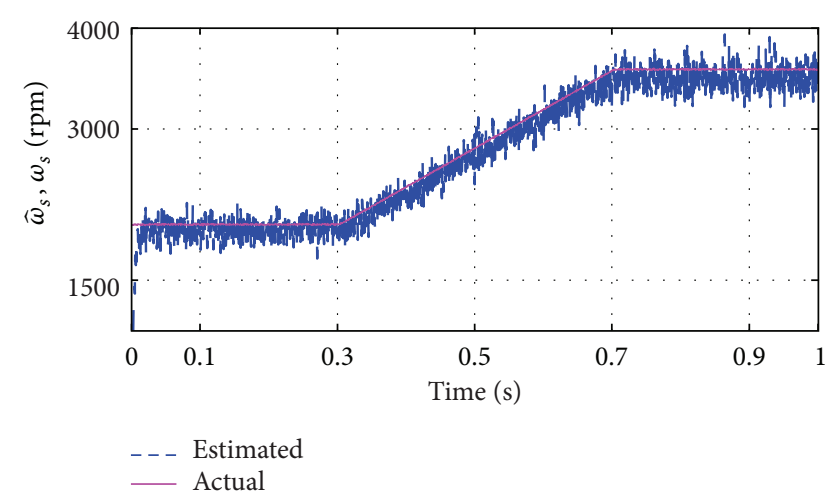

(a)

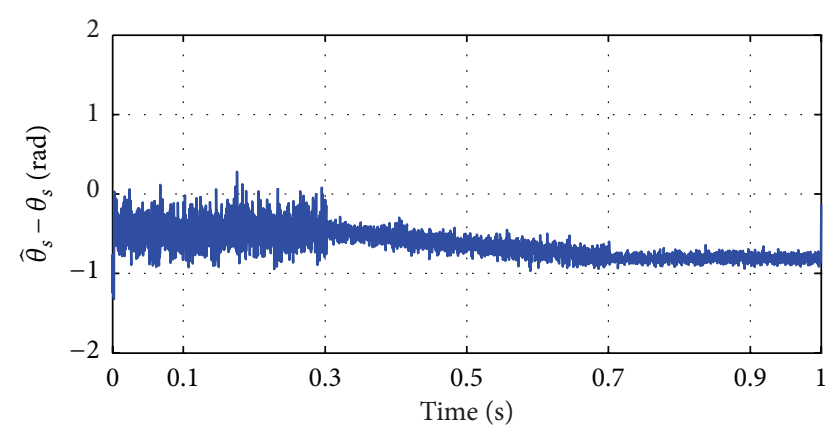

(b)

FIGURE 9: With conventional first-order SMO under load: (a) Estimated speed. (b) Rotor position estimation error.

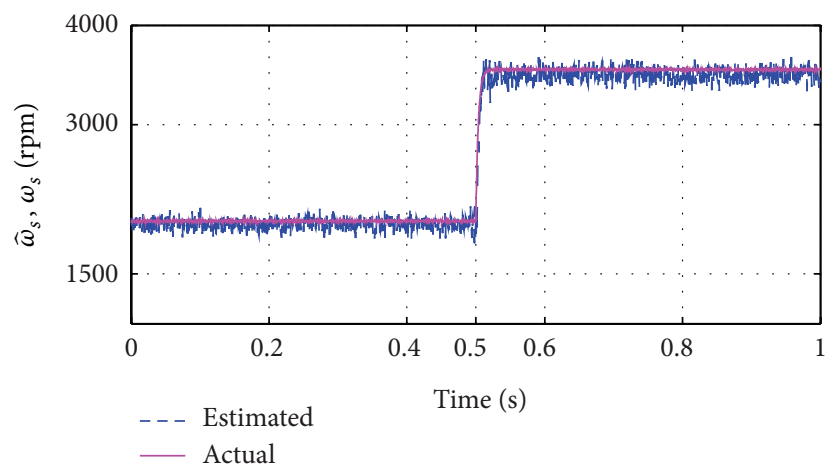

(a)

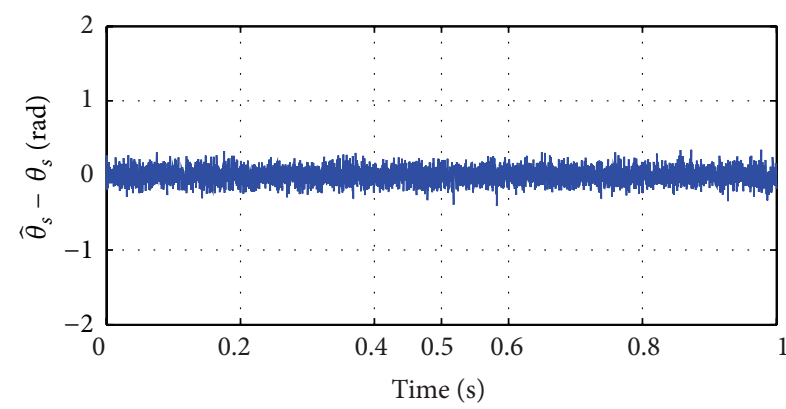

(b)

FIGURE 10: With proposed HOSM method under load. (a) Estimated speed. (b) Rotor position estimation error.

(4) Furthermore, compared to the classical first-order SM technique, no cutoff frequency has to be tuned. Instead, a simple integration is realized. It enables to reduce the time delay for the estimation (which depends on the sampling period). One should also highlight that the discontinuous part of $\phi_{2}$ (depending on $K_{4}$ ) is usually low compared to the continuous part of $\phi_{2}$ and this enables to reduce the chattering phenomenon.

(5) Moreover, from the experiments, the proposed method is robust to the parameter variations and the measurement noise compared to the traditional SM observer.

(6) It is worth to point out that the proposed method is computationally complex compared to the traditional SM observer. However, if properly tuned, it has more advantages than the traditional SM observer. The experiments conducted in this paper validate the advantages of this method.

(7) For the same set of parameters, the speed and position estimation remained accurate for both no-loading and loading conditions. This further highlights the robustness of the proposed method to parameter variations that occur with loading and other conditions.

\section{Conclusion}

This paper has presented a sensorless speed estimation method for the PMSM drive. The HOSM method is based on a modified version of super-twisting algorithm. The observer dynamics consist of sliding mode terms which are used to reconstruct the unknown back EMFs. The speed is then analytically computed from back EMFs. Experimental results validate the feasibility and effectiveness of the proposed HOSM for estimating the rotor position and speed of the PMSM. Compared with the traditional SMO, the proposed higher-order SMO provides better estimation performance.

\section{Appendix}

\section{Finite-Time Stability}

For any vector $z=\left[z_{1}, \ldots, z_{q}\right]^{T} \in R^{q}$ and any scalar $\alpha \in R$, we denote the following:

$$
\begin{gathered}
\operatorname{sign}(z)=\left[\operatorname{sign}\left(z_{1}\right), \ldots, \operatorname{sign}\left(z_{q}\right)\right]^{T}, \\
|z|^{\alpha}=\operatorname{diag}\left(\left|z_{1}\right|^{\alpha}, \ldots,\left|z_{q}\right|^{\alpha}\right), \\
\lceil z\rfloor^{\alpha}=|z|^{\alpha} \operatorname{sign}(z) .
\end{gathered}
$$




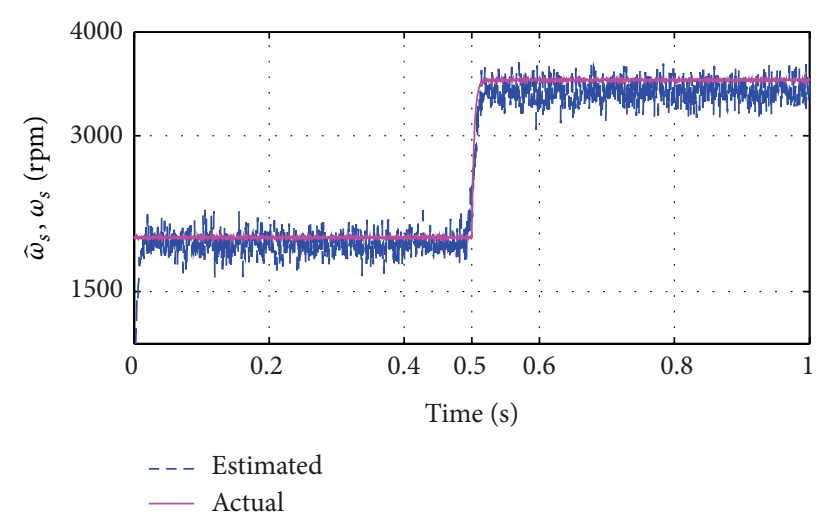

(a)

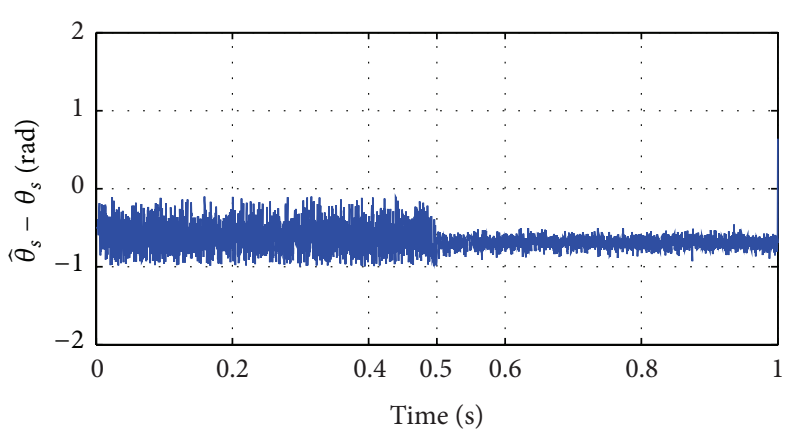

(b)

FIGURE 11: With conventional first-order SMO under load. (a) Estimated speed. (b) Rotor position estimation error.

For ease of exposition, consider the following system:

$$
\begin{aligned}
\dot{s}(t) & =-a s(t)+\nu(t)+e(s, t) \\
s\left(t_{0}\right) & =s_{0},
\end{aligned}
$$

where $s \in \mathscr{R}$ and $a$ is a known positive constant and $e(s, t)$ is the unknown input/perturbation and

$$
v(t)=-K_{1} \phi_{1}(s(t))-K_{2} \int_{0}^{t} \phi_{2}(s(t)) d t
$$

where $\phi_{1}(s(t))$ and $\phi_{2}(s(t))$ are defined in $(7)$ and $K_{1}, K_{2}, K_{3}$, and $K_{4}$ are appropriately designed positive constants.

Assumption A.1. The time derivative of the unknown input/perturbation is upper bounded as follows:

$$
|\dot{e}(s, t)| \leq \rho
$$

for a positive constant $\rho$.

Remark A.2. The sliding dynamics $s_{\alpha}$ or $s_{\beta}$ in (8) can be directly expressed in the form of (A.2). Further, the condition (9) is similar to Assumption A.1.

Proposition A.3. Under Assumption A.1, the origin of system (A.2) is a finite time stable equilibrium point. Further, the finite-time smooth estimation of the unknown input/perturbation e $(s, t)$ is given by $K_{2} \int_{0}^{t} \phi_{2}(s(t)) d t$.

Proof. Proof follows the work given in [20]. Since $\left|\phi_{2}(s)\right| \geq$ $K_{4}^{2} / 2$, one gets:

$$
|\dot{e}(s, t)| \leq\left|\phi_{2}(s)\right|
$$

if

$$
K_{4} \geq \sqrt{2 \rho} .
$$

Let us select a Hurwitz matrix $A_{0}$ :

$$
A_{0}=\left[\begin{array}{cc}
-\left(K_{1}+a\right) & 1 \\
-K_{2} & 0
\end{array}\right]
$$

where $K_{1}>0$ and $K_{2}>0$.
The system (A.2), (A.3) can be equivalently represented by the system of two first-order equations:

$$
\begin{aligned}
& \dot{s}_{1}=s_{2}-\left(K_{1}+a\right)\left(s_{1}+K_{4}\left\lceil s_{1}\right\rfloor^{1 / 2}\right), \\
& \dot{s}_{2}=-K_{2}\left(s_{1}+\frac{K_{4}^{2}}{2} \operatorname{sign}\left(s_{1}\right)+\frac{3}{2} K_{4}\left\lceil s_{1}\right\rfloor^{1 / 2}\right)+\dot{e}
\end{aligned}
$$

with $s_{1}=s, s_{2}=e-K_{2} \int_{0}^{t} \phi_{2}\left(s_{1}\right) d t$ and

$$
K_{4}=\frac{K_{1} K_{3}}{K_{1}+a}
$$

The solutions of the discontinuous differential equations and inclusions are understood in the sense of Filippov.

Let us consider the new state vector:

$$
\xi=\left[\begin{array}{l}
\xi_{1} \\
\xi_{2}
\end{array}\right]=\left[\begin{array}{c}
s_{1}+K_{4}\left\lceil s_{1}\right\rfloor^{1 / 2} \\
s_{2}
\end{array}\right]
$$

The stability analysis of system (A.8) is performed using the following candidate Lyapunov function [20]:

$$
V(\xi)=\xi^{T} P \xi
$$

with $P=P^{T}=\left[\begin{array}{cc}\lambda+4 \epsilon^{2} & -2 \epsilon \\ -2 \epsilon & 1\end{array}\right], \lambda>0$ and $\epsilon>0$. It is worth noting that the matrix $P$ is positive definite if $\lambda$ and $\epsilon$ are any real number.

Using the differential equations inclusion theory, its time derivative along the solutions of the system is given by

$$
\dot{V}=\left(1+\frac{K_{4}}{2}\left|s_{1}\right|^{-1 / 2}\right) \xi^{T}\left(A_{0}^{T} P+P A_{0}\right) \xi+2 \xi^{T} P\left[\begin{array}{l}
0 \\
\dot{e}
\end{array}\right] .
$$


It can be shown that

$$
\begin{aligned}
\dot{V} & \leq\left(1+\frac{K_{4}}{2}\left|s_{1}\right|^{-1 / 2}\right)\left(\xi^{T}\left(A_{0}^{T} P+P A_{0}\right) \xi+2 \xi^{T} P\left[\begin{array}{c}
0 \\
\xi_{1}
\end{array}\right]\right) \\
& \leq-\left(1+\frac{K_{4}}{2}\left|s_{1}\right|^{-1 / 2}\right) \xi^{T} Q \xi \\
& \leq-\left(1+\frac{K_{4}}{2}\left|s_{1}\right|^{-1 / 2}\right) \lambda_{\min }(Q)\|\xi\|^{2}
\end{aligned}
$$

with

$$
\begin{aligned}
Q & =\left[\begin{array}{ll}
Q_{1} & Q_{2} \\
Q_{2} & Q_{3}
\end{array}\right], \\
Q_{1} & =2\left(K_{1}+a\right)\left(\lambda+4 \epsilon^{2}\right)-4 \epsilon\left(K_{2}-1\right), \\
Q_{2} & =-2 \epsilon\left(K_{1}+a\right)+\left(K_{2}+1\right)-\left(\lambda+4 \epsilon^{2}\right), \\
Q_{3} & =4 \epsilon .
\end{aligned}
$$

In order to guarantee the positive definiteness of matrix $Q$, one chooses

$$
K_{2}=\lambda+4 \epsilon^{2}+2 \epsilon\left(K_{1}+a\right) .
$$

The matrix $Q$ is positive definite if

$$
K_{1}>-a+\frac{4 \epsilon+2 \epsilon \lambda+8 \epsilon^{3}}{\lambda}+\frac{1}{4 \epsilon \lambda} .
$$

From (A.10), one can deduce that

$$
\begin{aligned}
\|\xi\|^{2} & =\xi_{1}^{2}+\xi_{2}^{2} \\
& =s_{1}^{2}+2 K_{4}\left|s_{1}\right|^{3 / 2}+K_{4}^{2}\left|s_{1}\right|+\xi_{2}^{2} \\
& \geq K_{4}^{2}\left|s_{1}\right| .
\end{aligned}
$$

Since $K_{4}>0$

$$
-\frac{K_{4}}{\|\xi\|} \geq-\left|s_{1}\right|^{-1 / 2}
$$

It implies that

$$
\dot{V} \leq-\frac{\lambda_{\min }(Q)}{\lambda_{\max }^{1 / 2}(P)} \frac{K_{4}^{2}}{2} V^{1 / 2}-\frac{\lambda_{\text {min }}(Q)}{\lambda_{\text {max }}(P)} V .
$$

The closed-loop system (A.8) is stabilized in finite time. Since $\|\xi\|$ converges to zero in finite time, $s_{1}$ and $s_{2}$ converge to 0 . Therefore, the term $K_{2} \int_{0}^{t} \phi_{2}(s(t)) d t$ gives in finite time a smooth estimation of the unknown perturbation $e(s, t)$.

\section{Nomenclature}

$\omega_{s}$ : $\quad$ Rotor electrical speed

$i_{\alpha}, i_{\beta}$ : Currents in stationary reference frame

$V_{\alpha}, V_{\beta}$ : Voltages in stationary reference frame

$e_{\alpha}, e_{\beta}$ : EMFs in stationary reference frame

$R: \quad$ Stator resistance

$L: \quad$ Synchronous inductance

$K_{E}: \quad$ EMF constant

$\theta_{s}: \quad$ Rotor position angle

$T_{l}$ : Load torque.

\section{Conflict of Interests}

The authors declare that there is no conflict of interests regarding the publication of this paper.

\section{Acknowledgment}

This research was supported by the Basic Science Research Program through the National Research Foundation of Korea (NRF) funded by the Ministry of Education, Science and Technology (Grant no. 2011-0023999).

\section{References}

[1] R. Wu and G. R. Slemon, "A permanent magnet motor drive without a shaft sensor," IEEE Transactions on Industry Applications, vol. 27, no. 5, pp. 1005-1011, 1991.

[2] P. Tomei and C. M. Verrelli, "Observer-based speed tracking control for sensorless permanent magnet synchronous motors with unknown load torque," IEEE Transactions on Automatic Control, vol. 56, no. 6, pp. 1484-1488, 2011.

[3] V. Utkin, J. G. Guldner, and J. Shi, Sliding Mode Control on Electromechanical Systems, Taylor and Francis, New York, NY, USA, 1st edition, 1999.

[4] S. Chai, L. Wang, and R. Rogers, "Model predictive control of a permanent magnet synchronous motor with experimental validation," Control Engineering Practice, vol. 21, no. 11, pp. 15841593, 2013.

[5] T. Orlowska-Kowalska and M. Dybkowski, "Stator-currentbased MRAS estimator for a wide range speed-sensorless induction-motor drive," IEEE Transactions on Industrial Electronics, vol. 57, no. 4, pp. 1296-1308, 2010.

[6] M. L. Corradini, G. Ippoliti, S. Longhi, and G. Orlando, "A quasi-sliding mode approach for robust control and speed estimation of PM synchronous motors," IEEE Transactions on Industrial Electronics, vol. 59, no. 2, pp. 1096-1104, 2012.

[7] B. K. Bose, Modern Power Electronics and AC Drives, PrenticeHall, Upper Saddle River, NJ, USA, 2002.

[8] K. C. Veluvolu and Y. C. Soh, "Multiple sliding mode observers and unknown input estimations for Lipschitz nonlinear systems," International Journal of Robust and Nonlinear Control, vol. 21, no. 11, pp. 1322-1340, 2011.

[9] K. C. Veluvolu and D. Lee, "Sliding mode high-gain observers for a class of uncertain nonlinear systems," Applied Mathematics Letters, vol. 24, no. 3, pp. 329-334, 2011.

[10] K. C. Veluvolu and Y. C. Soh, "Fault reconstruction and state estimation with sliding mode observers for Lipschitz non-linear systems," IET Control Theory \& Applications, vol. 5, no. 11, pp. 1255-1263, 2011.

[11] M. Comanescu and L. Xu, "Sliding-mode MRAS speed estimators for sensorless vector control of induction machine," IEEE Transactions on Industrial Electronics, vol. 53, no. 1, pp. 146-153, 2006.

[12] Z. Qiao, T. Shi, Y. Wang, Y. Yan, C. Xia, and X. He, "New slidingmode observer for position sensorless control of permanentmagnet synchronous motor," IEEE Transactions on Industrial Electronics, vol. 60, no. 2, pp. 710-719, 2013.

[13] K. C. Veluvolu, M. Y. Kim, and D. Lee, "Nonlinear sliding mode high-gain observers for fault estimation," International Journal of Systems Science: Principles and Applications of Systems and Integration, vol. 42, no. 7, pp. 1065-1074, 2011. 
[14] K. C. Veluvolu, M. Defoort, and Y. C. Soh, "High-gain observer with sliding mode for nonlinear state estimation and fault reconstruction," Journal of the Franklin Institute: Engineering and Applied Mathematics, vol. 351, no. 4, pp. 1995-2014, 2014.

[15] M. Comanescu, "Cascaded EMF and speed sliding mode observer for the nonsalient PMSM," in Proceedings of the 36th Annual Conference of the IEEE Industrial Electronics Society (IECON '10), pp. 792-797, Glendale, Ariz, November 2010.

[16] M. Comanescu, "An induction-motor speed estimator based on integral sliding-mode current control," IEEE Transactions on Industrial Electronics, vol. 56, no. 9, pp. 3414-3423, 2009.

[17] X. Yu and O. Kaynak, "Sliding-mode control with soft computing: a survey," IEEE Transactions on Industrial Electronics, vol. 56, no. 9, pp. 3275-3285, 2009.

[18] M. Comanescu, L. Xu, and T. D. Batzel, "Decoupled current control of sensorless induction-motor drives by integral sliding mode," IEEE Transactions on Industrial Electronics, vol. 55, no. 11, pp. 3836-3845, 2008.

[19] H. Kim, J. Son, and J. Lee, "A high-speed sliding-mode observer for the sensorless speed control of a PMSM," IEEE Transactions on Industrial Electronics, vol. 58, no. 9, pp. 4069-4077, 2011.

[20] J. A. Moreno and M. Osorio, "Strict Lyapunov functions for the super-twisting algorithm," IEEE Transactions on Automatic Control, vol. 57, no. 4, pp. 1035-1040, 2012.

[21] T. Floquet and J. P. Barbot, "Super twisting algorithm-based step-by-step sliding mode observers for nonlinear systems with unknown inputs," International Journal of Systems Science: Principles and Applications of Systems and Integration, vol. 38, no. 10, pp. 803-815, 2007.

[22] J. J. Rath, K. C. Veluvolu, M. Defoort, and Y. C. Soh, "Higherorder sliding mode observer for estimation of tyre friction in ground vehicles," IET Proceedings on Control Theory and Applications, vol. 8, no. 6, pp. 399-408, 2014.

[23] L. Fridman and A. Levant, "Higher order sliding modes. Sliding mode control in engineering," in Sliding Mode Control in Engineering, J. P. Barbot and W. Perruquetti, Eds., Marcel Dekker, New York, NY, USA, 2002.

[24] M. Ezzat, J. De Leon, N. Gonzalez, and A. Glumineau, "Observer-controller scheme using high order sliding mode techniques for sensorless speed control of permanent magnet synchronous motor," in Proceedings of the 49th IEEE Conference on Decision and Control (CDC '10), pp. 4012-4017, December 2010.

[25] D. Zaltni and M. N. Abdelkrim, "Robust speed and position observer using H.O.S.M for sensor-less S.P.M.S.M control," in Proceedings of the 7th International Multi-Conference on Systems, Signals and Devices (SSD '10), pp. 1-6, June 2010. 


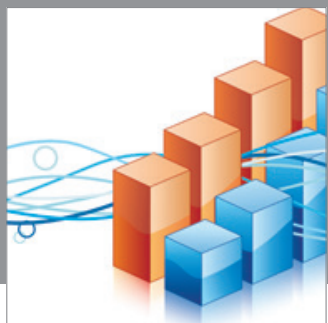

Advances in

Operations Research

mansans

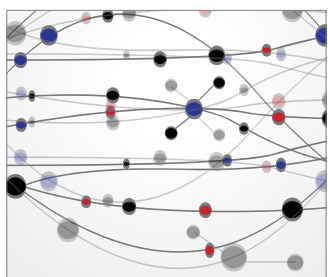

The Scientific World Journal
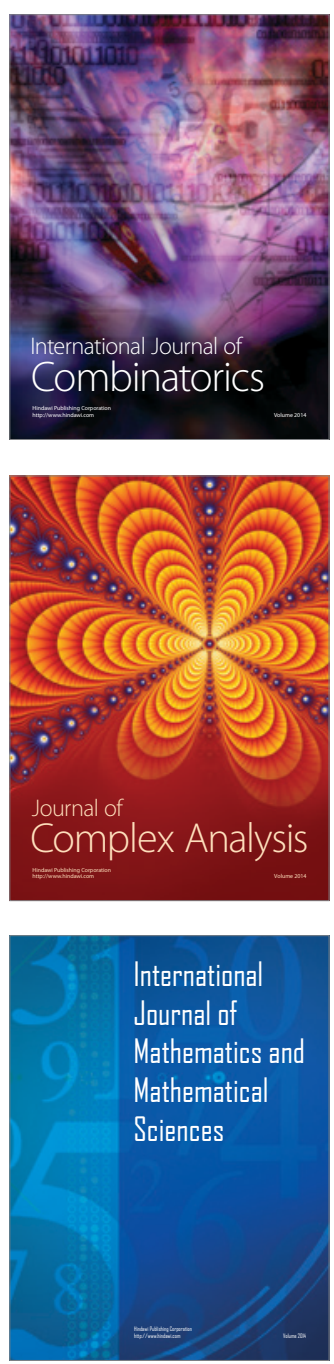
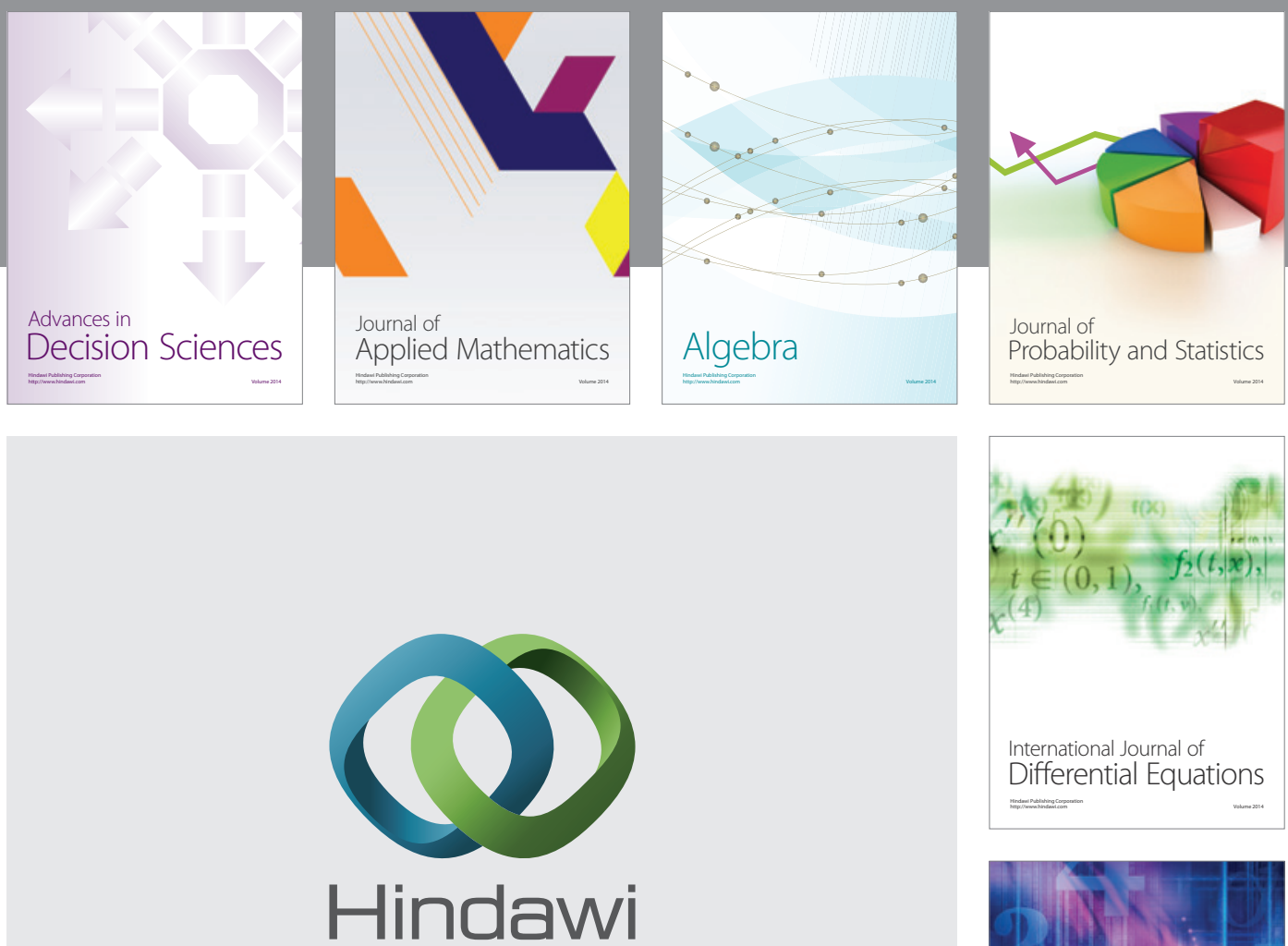

Submit your manuscripts at http://www.hindawi.com
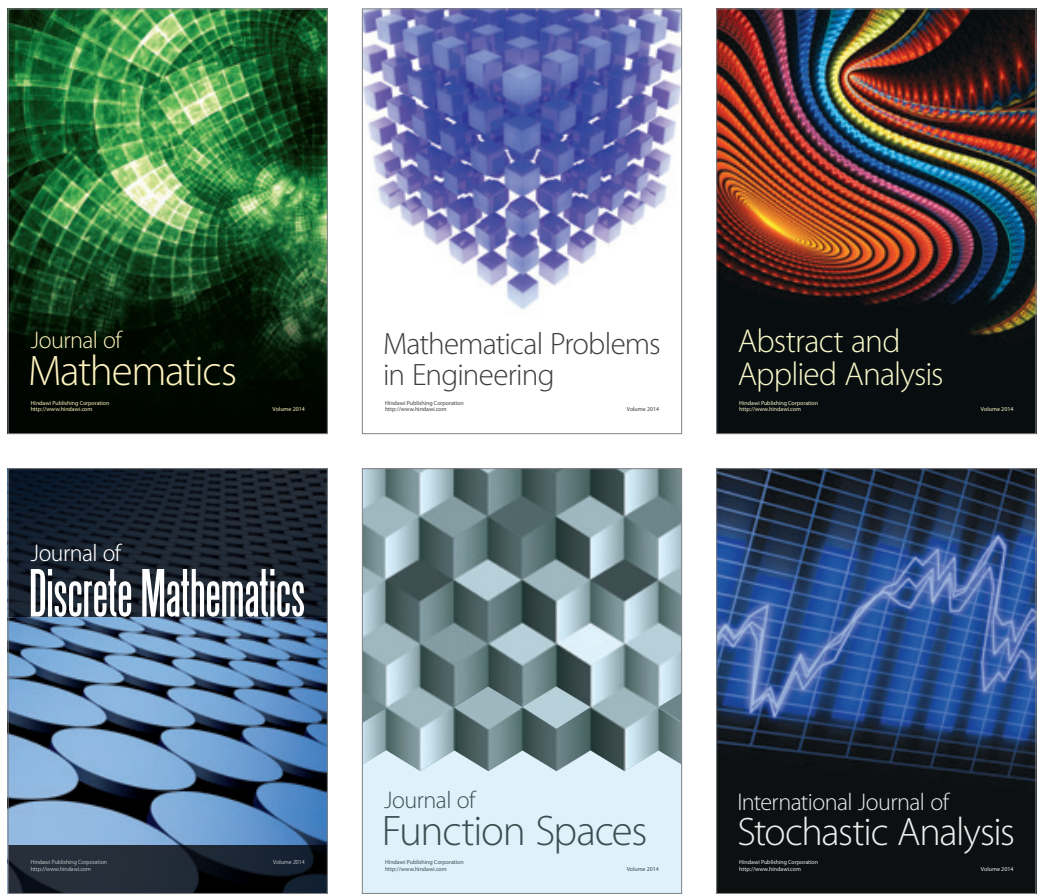

Journal of

Function Spaces

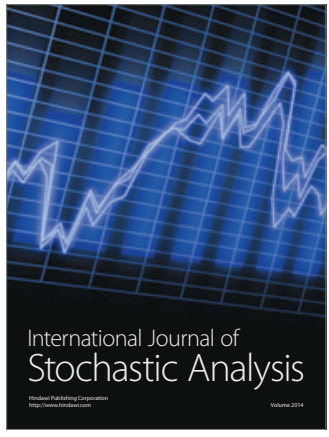

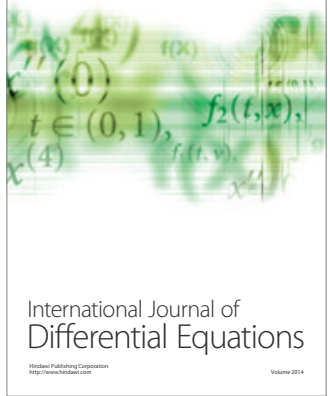
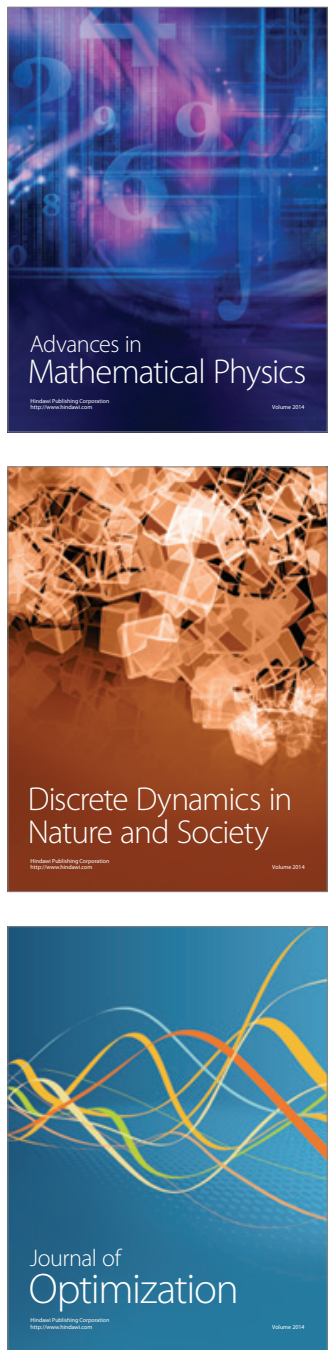